\title{
Search for intracranial aneurysm susceptibility gene(s) using Finnish families
}

\author{
Jane M Olson ${ }^{1}$, Sompong Vongpunsawad ${ }^{2}$, Helena Kuivaniemi ${ }^{3}$, \\ Antti Ronkainen ${ }^{4}$, Juha Hernesniemi ${ }^{4,6}$, Markku Ryynänen ${ }^{5,7}$, Lee-Lian Kim ${ }^{1}$ \\ and Gerard Tromp*2
}

Address: ${ }^{1}$ Department of Epidemiology and Biostatistics, Case Western Reserve University, Cleveland, Ohio USA, ${ }^{2}$ Center for Molecular Medicine and Genetics, Wayne State University School of Medicine, Detroit, Michigan, USA, ${ }^{3}$ Center for Molecular Medicine and Genetics, and Department of Surgery, Wayne State University School of Medicine, Detroit, Michigan, USA, ${ }^{4}$ Department of Neurosurgery University of Kuopio, Kuopio, Finland, ${ }^{5}$ Department of Obstetrics and Gynecology, University of Kuopio, Kuopio, Finland, ${ }^{6}$ Department of Neurosurgery, University of Helsinki, Helsinki, Finland and ${ }^{7}$ Department of Obstetrics and Gynecology, University of Oulu, Oulu, Finland

E-mail: Jane M Olson - olson@darwin.epbi.cwru.edu; Sompong Vongpunsawad - vongpunsawad.sompong@mayo.edu; Helena Kuivaniemi - helena.kuivaniemi@sanger.med.wayne.edu; Antti Ronkainen - antti.ronkainen@kuh.fi; Juha Hernesniemi - juha.hernesniemi@hus.fi; Markku Ryynänen - markku.ryynanen@oulu.fi; Lee-Lian Kim - leelian_kim@merck.com; Gerard Tromp* - gerard.tromp@sanger.med.wayne.edu

*Corresponding author

This article is available from: http://www.biomedcentral.com/I47I-2350/3/7

(C) 2002 Olson et al; licensee BioMed Central Ltd. This article is published in Open Access: verbatim copying and redistribution of this article are permitted in all media for any non-commercial purpose, provided this notice is preserved along with the article's original URL.

\begin{abstract}
Background: Cerebrovascular disease is the third leading cause of death in the United States, and about one-fourth of cerebrovascular deaths are attributed to ruptured intracranial aneurysms (IA). Epidemiological evidence suggests that IAs cluster in families, and are therefore probably genetic. Identification of individuals at risk for developing IAs by genetic tests will allow concentration of diagnostic imaging on high-risk individuals. We used model-free linkage analysis based on allele sharing with a two-stage design for a genome-wide scan to identify chromosomal regions that may harbor IA loci.
\end{abstract}

Methods: We previously estimated sibling relative risk in the Finnish population at between 9 and 16, and proceeded with a genome-wide scan for loci predisposing to IA. In 85 Finnish families with two or more affected members, 48 affected sibling pairs (ASPs) were available for our genetic study. Power calculations indicated that 48 ASPs were adequate to identify chromosomal regions likely to harbor predisposing genes and that a liberal stage I lod score threshold of 0.8 provided a reasonable balance between detection of false positive regions and failure to detect real loci with moderate effect.

Results: Seven chromosomal regions exceeded the stage I lod score threshold of 0.8 and five exceeded 1.0. The most significant region, on chromosome 19q, had a maximum multipoint lod score (MLS) of 2.6.

Conclusions: Our study provides evidence for the locations of genes predisposing to IA. Further studies are necessary to elucidate the genes and their role in the pathophysiology of IA, and to design genetic tests. 


\section{Background}

In spite of advances in surgical and pharmacological treatment, about half of the aneurysmal subarachnoid hemorrhage (SAH) patients die and many who survive need rehabilitation to maintain independence, causing significant economic losses to medical and social care. About $90 \%$ of SAH cases are caused by a ruptured IA [1]. Per-case mortality for ruptured IAs is about 30 to $50 \%$ and morbidity about $66 \%$ as opposed to about $2 \%$ mortality and $4 \%$ morbidity for elective surgery of unruptured IAs in asymptomatic low-risk patients [2,3]. Given the marked contrast between the outcomes of elective versus emergency surgery, the goal has to be identification and treatment of IAs prior to rupture.

There is substantial debate regarding the cost-benefit ratio of population screening [4-8]. Restricting screening to those individuals at high risk both for developing IA and for rupture would improve the cost-benefit ratio. Characterization of environmental and genetic risk factors would allow not only reduction of risk through behavior modification, but also significantly improve detection. Additionally, some environmental and genetic risk factors may be amenable to pharmacological intervention. Simple tests for genetic risk factors would permit the identification of individuals at high risk for development and rupture of aneurysms, consequently allowing diagnostic effort to be concentrated on a smaller group that is at higher risk.

Currently, several risk factors have been identified including cigarette smoking, arterial hypertension, gender, aging, atherosclerosis and heavy alcohol consumption [912]. Initial indications of a genetic component were based on collections of case reports that suggested that IAs are associated with some rare simple Mendelian disorders, e.g. autosomal dominant polycystic kidney disease, Ehlers Danlos syndrome type IV and the Marfan syndrome [13]. More recent systematic prevalence estimates indicate either absence of association or markedly reduced prevalence of IA among patients with rare simple Mendelian disorders $[14,15]$. Also, genetic analyses of genes known to cause some simple Mendelian disorders have proven negative for collections of patients with IA $[16,17]$. The familial occurrence of IAs not associated with known simple Mendelian disorders was first noted in 1942 [18] and, since then, nearly one hundred case reports and review articles have been published. Population-based studies of SAH probands show that 7 to $10 \%$ have a family history of IA, a higher percentage than previously appreciated $[1,19,20]$. These familial IA (FIA) families have no signs of any other simple Mendelian disorders predisposing to IA, supporting the possibility that some or all IAs have a genetic component, and that FIA is a genetic disease separate and apart from previously defined diseases. The inheritance patterns of FIA have not been determined, partly be- cause IA is a late age-at-onset disease and partly because it is likely to be a multifactorial disease for which simple Mendelian models will not fit well [1,21-23].

\section{Methods \\ Study subjects}

Eighty-five families with at least two members with ruptured or unruptured IA and no family history of polycystic kidney disease were ascertained from a sampling frame of 1150 consecutive patients treated between 1977 and 1990 for aneurysmal SAH by the Department of Neurosurgery at the University Hospital of Kuopio, which serves a genetically homogenous population of 870,000 in eastern Finland [1]. Initially, family history was assessed by a short questionnaire and all putative cases were confirmed from medical and autopsy records. Due to the high mortality of IA and lack of pre-rupture symptoms, surviving relatives with known IA were rare. We therefore used magnetic resonance angiography to screen 264 siblings over the age of 30 of the IA probands [1]. Positive magnetic resonance angiography findings were then confirmed using digital subtraction angiography. Upper-abdominal ultrasonography was performed on all screened individuals and confirmed that none of these individuals had evidence of polycystic kidney disease. In this manner, we detected 30 siblings with asymptomatic IA, giving a total of 49 affected sib pairs from 25 sibships (22 extended families; families 10, 21 and 29 had two sibships each; Figure 1 and Table 1). One non-sib pair was detected in one of the sibships in family 21 (see Statistical analyses below; Figure 1) and eliminated from the analyses, leaving 48 ASPs for the genome scan. The ASPs were comprised of 26 males and 34 females. Blood samples were obtained from affected family members, unaffected siblings, and parents, where possible. Due to the late age at onset, parents were available in only a few of the families. All family records were confirmed through registries kept by the Evangelical Lutheran Church of Finland.

The study protocol was reviewed and approved by the Institutional Review Boards of both the University Hospital of Kuopio and Wayne State University.

\section{Study design}

Whole-genome scans are labor-intensive and costly since each individual in the study must be genotyped for all markers. Reduction of the number of samples genotyped, or the number of markers, or both, has been shown to be efficient [24-28]. We used a two-stage design. In stage 1, samples are genotyped at low density and subsequently at higher density in stage 2, thereby reducing the overall number of markers genotyped. Stage 1 data were analysed using a liberal $\alpha \approx 0.05$ (lod $=0.8)$. Regions exceeding the threshold were genotyped in stage 2 . 

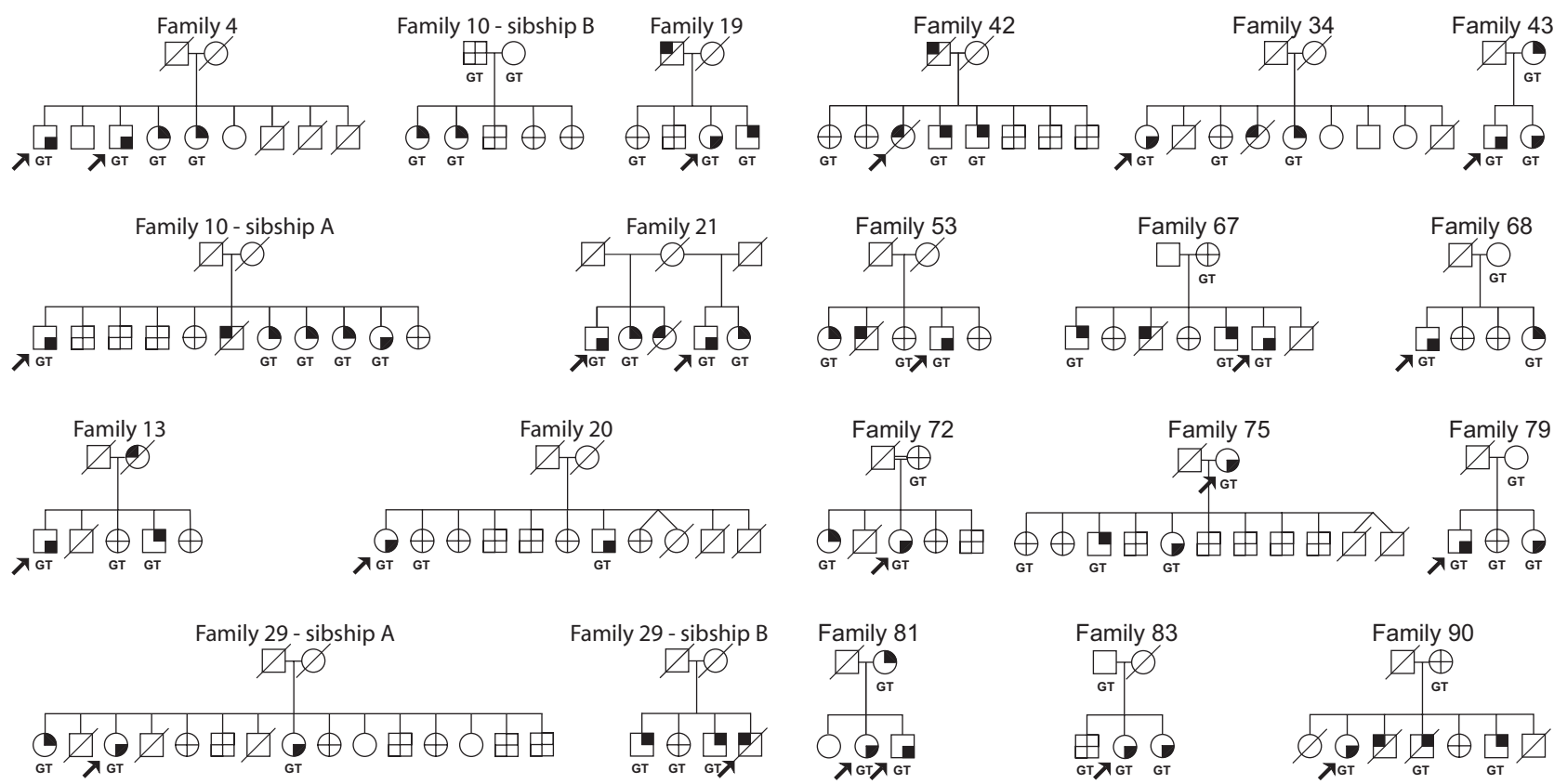

Family 75
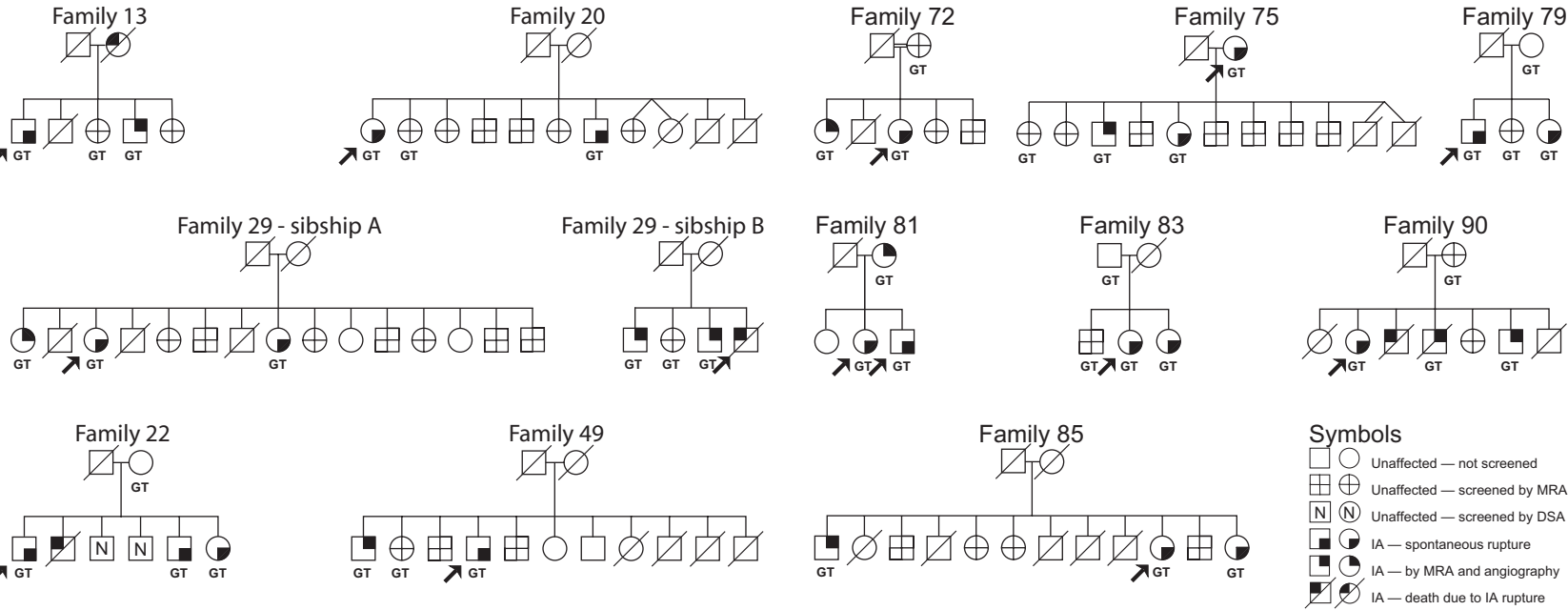

\section{Figure I}

FIA Pedigrees. The genome scan was performed with the 48 of 49 affected sibling pairs from the 24 sibships since one of the pairs in family 21 was determined to be a non-sib pair. GT indicates that DNA from the corresponding individual was genotyped. Symbols are defined in the figure: DSA denotes digital subtractive angiography; MRA denotes magnetic resonance angiography.

Power was computed assuming a two-stage design, 49 ASPs, and a map density of $15 \mathrm{cM}$. For stage I alone, we had at least $96 \%$ power to detect "significant linkage" (lod score of 3.6) [29] to a locus with a locus-specific relative risk to siblings of 8 and at least $90 \%$ power to detect "suggestive linkage" to a locus with a locus-specific relative risk of 4 .

\section{DNA isolation and pre-amplification}

Blood was collected into EDTA-containing tubes. Genomic DNA was isolated either by an automated procedure (Genepure DNA extractor, Applied Biosystems, Inc., Foster City, CA) or manually (Puregene DNA isolation kit, Gentra Systems, Inc., Minneapolis, MN). Genotyping was performed using genomic DNA, either untreated or amplified linearly using primer-extension preamplification [30,31]. Approximately $0.5 \mu \mathrm{g}$ genomic DNA was used for preamplification with an $\mathrm{N}_{15}$-primer $[30,31]$. The result- ing preamplified DNA was then used as a template in marker PCRs with specific primers.

\section{Genotyping}

Most of the initial genotyping was performed by the National Heart Lung and Blood Institute Mammalian Genotyping Service at the Marshfield Research Foundation using the $10 \mathrm{cM}$ Weber version 8 screening set [32]. Primer pairs for additional markers were obtained from Research Genetics, Inc. (Huntsville, AL). For the additional genotyping, PCRs were carried out with one of the primers radioactively labeled. PCRs were set up using a laboratory workstation (Biomek 1000; Beckman, Palo Alto, CA) and performed in PEC 9600 thermal cyclers (Perkin Elmer Cetus, Foster City, CA). The alleles were scored visually from autoradiographs and entered into an Oracle database (Oracle Corp., Redwood Shores, CA). Population frequencies for each marker were estimated from a sample of 20 to 24 unrelated Finnish subjects. 
Table I: Distribution of Affected Sibship Sizes

\begin{tabular}{ccc}
\hline Affected Siblings & Sibships & Affected Pairs \\
\hline 2 & 18 & 18 \\
3 & 5 & 15 \\
4 & 1 & 6 \\
5 & 1 & 10 \\
\hline
\end{tabular}

\section{Statistical analyses}

A Markov-process-based test of genetic relationship [33] using all the marker data across the genome was used on each nuclear family to confirm the sib-pair relationship; one non-sib pair was detected in one of the sibships in family 21 (Figure. 1) and eliminated from the analyses. The results were consequently derived from 24 sibships (Figure 1).

The genotype data were analyzed for genetic linkage with both single-marker and multipoint model-free ASP lod score analysis [34] using the computer program MAPMAKER/SIBS [35].

\section{Results}

\section{Genome-wide linkage analysis}

We performed stage I of a two-stage genome scan using the 48 Finnish ASPs. Due to the genetic homogeneity of the Finnish population [36-40] the probability of identifying genetic risk factors in a complex disease such as FIA may be substantially improved $[37,38,40]$. In the first stage a $10 \mathrm{cM}$ genome scan was performed using the Weber screening set 8 [32] and the data analyzed using both two-point and multipoint ASP linkage analysis. Seven regions on chromosomes $4,6,7 \mathrm{p}, 7 \mathrm{q}, 14,19$, and $\mathrm{X}$, with multipoint lod scores exceeding 0.8 (pointwise P-value $\approx$ 0.05 ) were identified (Table 2). Two regions had MLSs exceeding 2.0 (2.58 on chromosome $19 ; 2.08$ on chromosome X). Two-point lod scores exceeded 1.0 for two adjacent markers in each of these regions, ruling out substantial genotyping error in one marker as the cause of the high lod scores. Three additional regions with multipoint lod scores exceeding 0.8 (chromosomes 4,6 , and $7 \mathrm{q}$ ) also had substantial two-point lod scores at more than one marker. For two regions ( $7 p$ and $14 q)$, however, only one marker had a high two-point lod score. In both cases, the significant marker was either the first or the last marker typed on the chromosome. Following conventional guidelines, we considered an MLS of 3.6 or greater to be "significant linkage" and an MLS of 2.2 to be "suggestive linkage" [29].
In stage 2, we genotyped additional markers in the seven regions identified in stage 1 . Four additional markers flanking D7S1819 on 7p and nine additional markers flanking D14S1434 on 14q were typed and the resulting maximum MLSs were $0.28(7 p)$ and $0.80(14 q)$, indicating that the previous linkage signals were likely due to the increased statistical variability commonly seen in the multipoint signal at the most extreme markers. We therefore eliminated regions $7 p$ and $14 q$ from further consideration. Additional markers were typed in the two regions on chromosome 19 and X with maximum MLSs exceeding 2.0. A multipoint plot for the chromosome 19 is shown in Figure 2; the maximum MLS was 2.58 at D19S245 - D19S246. The maximum MLS for chromosome X decreased from 2.08 at DXS987 to 1.33 at DXS1226, (about $10 \mathrm{cM}$ centromeric from DXS987). The MLS for the region on chromosome X decreased considerably with the addition of several new markers and consequent improvement in the accuracy of the multipoint allele-sharing estimates, which were clearly overestimated when only the initial scan markers were included in the analysis. All the evidence for linkage in this region was due to 8 brother-brother pairs; the 16 sister-sister pairs and the 25 brother-sister pairs gave maximum MLSs close to zero in this region.

\section{Discussion}

The relatively high prevalence of IAs and aneurysmal SAH place the disease in the group of moderately common disorders. Consequently, it shares some of the features that make common disorders complex with respect to genetic analysis. These include: low sibling relative risks due to

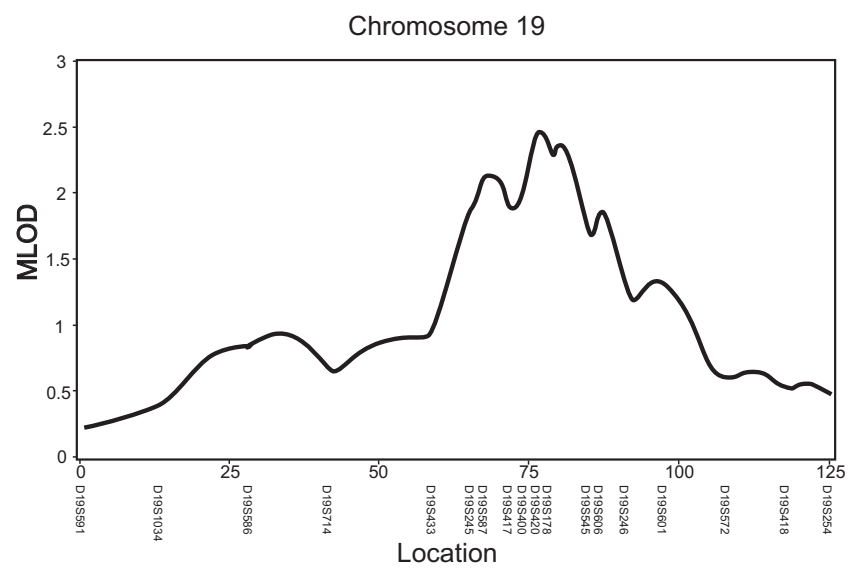

\section{Figure 2}

Chromosome 19 multipoint lod score versus genetic distance (cM). Also indicated below the CM scale are the polymorphic markers. 
Table 2: Maximum MLSs for the seven regions exceeding the stage I threshold

\begin{tabular}{|c|c|c|c|}
\hline Chromosome & MMLS & Distance (cM) from pter & Marker(s) \\
\hline 4 & 1.27 & 8 & D4S2366 - D4S403 \\
\hline 6 & 1.20 & 106 & D6S103I \\
\hline 7 & 1.67 & 0 & D7SI8I9 (pter) \\
\hline 7 & 0.90 & 175 & D7S1824 \\
\hline 14 & 1.36 & 145 & DI4SI426 (qter) \\
\hline 19 & 2.58 & 69 & DI9S245 - DI9S246 \\
\hline$x$ & 2.08 & 18 & DXS987 \\
\hline
\end{tabular}

the high population prevalence; presence of multiple genetic loci, each contributing a small portion of the sibling relative risk; incomplete penetrance of genetic loci; environmental risk factors; late age at onset; and phenocopies, i.e. disease due to purely environmental factors. Additional complexity for genetic analysis arises due to diagnostic uncertainty. Several measures were taken to increase the probability of success. We used robust, model-free, allelesharing genetic analyses to address the complexity, we studied a relatively genetically homogenous population, and we verified that all putative IAs were saccular $[1,20,41-43]$. It is expected that a genetically homogeneous population, particularly one with a recent population bottleneck [37,38], segregates for fewer disease loci thereby allowing a smaller sample size to be informative. Additionally, our study design was cost-effective, two-stage design with 48 ASPs. We are collecting an additional 150 ASPs for further study.

The most promising locus with a maximum MLS of 2.6 was on chromosome 19. The peak is located approximately in $19 q 12-13$, a gene-rich region containing a number of loci related to cerebrovascular, cardiovascular and membrane physiology and pathobiology. These include urokinase-type plasminogen activator receptor (PLAUR; MIM 173391, see Online Mendelian Inheritance in Man [http://www.ncbi.nlm.nih.gov/omim/]) [44], apolipoproteins E (MIM 107741), CII (MIM 207750) and CI (MIM 107710), human brain-specific $\mathrm{Na}(+)$-dependent inorganic phosphate cotransporter (hBNPI, 19q13) [45], cardiac troponin I (TnIc, 19q; MIM 191044) [46,47], cerebral autosomal dominant arteriopathy with subcortical infarcts and leukoencephalopathy (CADASIL, caused by mutations in the Notch3 gene, 19q12; MIM 602275) [48], isolated cardiac conduction disease (19q13.3; MIM 113900) [49], and progressive familial heart block type I (PF-HBI, 19q13.2-13.3; MIM 113900) [50]. Mutations in the $\mathrm{P} / \mathrm{Q}$-type $\mathrm{Ca}(2+)$-channel alpha $1 \mathrm{~A}$-subunit gene on 19 q12 cause familial hemiplegic migraine, episodic ataxia type 2, and spinocerebellar ataxia type 6 (MIM 141500) [51,52].

It is noteworthy that none of the regions in which we found some evidence for linkage, either tentative or suggestive, are similar to the regions detected in another recent genome-wide scan for IA susceptibility genes [53]. Although our study found evidence for a region with tentative linkage on chromosome $7 \mathrm{q}$, the region identified in this study is near the telomere and does not overlap with the region of suggestive linkage near the centromere on $7 \mathrm{q}$ identified in Onda et al. [53]. The populations that were studied are distinct, Finns as compared to Japanese; however, both samples were small and it is therefore possible that there may yet be some overlap in genetic predisposition.

\section{Conclusions}

We detected two regions of suggestive linkage, one on chromosome 19 and the other on the X chromosome in a sample of Finnish ASPs. Although we initially detected regions of tentative linkage on chromosomes $4,6,7 \mathrm{p}, 7 \mathrm{q}$ and 14 , the regions on $7 \mathrm{p}$ and 14 were excluded upon additional genotyping. None of the regions detected in this study overlap with the regions detected in a sample of Japanese ASPs [53].

\section{Competing interests}

None declared.

\section{Authors' contributions}

Author 1 (JMO) participated in the study design and directed the statistical genetic analyses and provided substantial input to the manuscript. Author 2 (SV) performed most of the higher resolution genotyping. Author 3 (HK) participated in the study design and implementation, participated in DNA isolation and performed most of the primer-extension pre-amplification reactions. Author 4 (AR) participated in the design of the family collection, and contacted and collected the family information. Au- 
thor $5(\mathrm{JH})$ conceived of the family data collection and supervised AR. Author $6(\mathrm{MR})$ coordinated the collection of blood specimens. Author 7 (L-LK) performed the statistical analyses under the supervision of JMO. Author 8 (GT) participated in the study design and coordination, DNA isolation, genotyping, drafting the manuscript, and obtained funding for the study.

\section{All authors read and approved the final manuscript.}

\section{Acknowledgements}

We thank Dr. James Weber and the National Heart Lung and Blood Institute Mammalian Genotyping Service at the Marshfield Medical Research Foundation, Marshfield, WI, for performing the initial, and majority, of the genotyping for the genome scan.

Supported by funds from Wayne State University School of Medicine, University of Kuopio, the American Heart Association, Michigan Affiliate (to G.T.), a grant from the National Institute for Neurological Disorders and Stroke (NINDS) (NS34395 to G.T.), a grant from the National Center for Human Genome Research (HGO I577) (to J.M.O.) and a grant from the $\mathrm{Na}$ tional Center for Research Resources (RR03655).

\section{References}

I. Ronkainen A, Hernesniemi J, Puranen M, Niemitukia L, Vanninen R, Ryynänen M, Kuivaniemi H, Tromp G: Familial intracranial aneurysms. The Lancet 1997, 349:380-384

2. Heiskanen $O$ : Risks of surgery for unruptured intracranial aneurysms. Journal of Neurosurgery 1986, 65:45 I-453

3. King JT Jr, Berlin JA, Flamm ES: Morbidity and mortality from elective surgery for asymptomatic, unruptured, intracranial aneurysms: a meta-analysis. Journal of Neurosurgery 1994, 8 I :837842

4. Johnston SC, Gress DR, Kahn JG: Which unruptured cerebral aneurysms should be treated? A cost-utility analysis. Neurology 1999, 52:1806-1815

5. Crawley F, Clifton A, Brown MM: Should we screen for familial intracranial aneurysm? Stroke 1999, 30:312-316

6. Yoshimoto $Y$, Wakai S: Cost-effectiveness analysis of screening for asymptomatic, unruptured intracranial aneurysms: $A$ mathematical model. Stroke 1999, 30:1621-1627

7. King JT Jr, Glick HA, Mason TJ, Flamm ES: Elective surgery for asymptomatic, unruptured, intracranial aneurysms: a costeffectiveness analysis. Journal of Neurosurgery 1995, 83:403-4I2

8. ISUIA consortium: Unruptured intracranial aneurysms-risk of rupture and risks of surgical intervention. International Study of Unruptured Intracranial Aneurysms Investigators. New England Journal of Medicine 1998, 339:1725-1733

9. Weir B: Intracranial aneurysms and subarachnoid hemorrhage: an overview. In: Neurosurgery (Edited by: Wilkins RH, Rengarchy SS) New York: McGraw-Hill Book Company 1985, 2: I 308-I 329

10. Fogelholm R, Hernesniemi J, Vapalahti M: Impact of early surgery on outcome after aneurysmal subarachnoid hemorrhage. A population-based study. Stroke 1993, 24:1649-1654

II. Sekhar LN, Heros RC: Origin, growth, and rupture of saccular aneurysms: a review. Neurosurgery 1981, 8:248-260

12. Juvela S, Hillbom M, Numminen H, Koskinen P: Cigarette smoking and alcohol consumption as risk factors for aneurysmal subarachnoid hemorrhage. Stroke 1993, 24:639-646

13. Schievink WI: Intracranial aneurysms. New England Journal of Medicine 1997, 336:28-40

14. Cloft HJ, Kallmes DF, Kallmes MH, Goldstein JH, Jensen ME, Dion JE: Prevalence of cerebral aneurysms in patients with fibromuscular dysplasia: a reassessment. Journal of Neurosurgery 1998, 88:436-440

15. van den Berg JS, Limburg M, Hennekam RC: Is Marfan syndrome associated with symptomatic intracranial aneurysms? Stroke 1996, 27:10-12

16. Kuivaniemi H, Prockop DJ, Wu Y, Madhatheri SL, Kleinert C, Earley J, Jokinen A, Stolle C, Majamaa K, Myllyla VV, Norrgård Ö, Schievink WI, Mokri B, Fukawa O, ter Berg HWM, De Paepe A, Lozano AM,
Leblanc R, Ryynänen M, Baxter BT, Shikata H, Ferrell RE, Tromp G: Exclusion of mutations in the gene for type III collagen (COL3AI) as a common cause of intracranial aneurysms or cervical artery dissections: results from sequence analysis of the coding sequences of type III collagen from 55 unrelated patients. Neurology 1993, 43:2652-2658

17. van den Berg JS, Pals G, Arwert F, Hennekam RC, Albrecht KW, Westerveld A, Limburg $M$ : Type III collagen deficiency in saccular intracranial aneurysms: defect in gene regulation? Stroke 1999, 30:1628-1631

18. O'Brien JG: Subarachnoid hemorrhage in identical twins. British Medical Journal 1942, 607-609

19. Norrgård Ö, Ängquist KA, Fodstad H, Forsell Ä, Lindberg M: Intracranial aneurysms and heredity. Neurosurgery 1987, 20:236-239

20. Ronkainen A, Hernesniemi J, Ryynänen M: Familial subarachnoid hemorrhage in east Finland, 1977-1990. Neurosurgery 1993, 33:787-796

21. Schievink WI, Schaid DJ, Rogers HM, Piepgras DG, Michels VV: On the inheritance of intracranial aneurysms. Stroke 1994, 25:2028-2037

22. Ronkainen A, Hernesniemi J, Tromp G: Special features of familial intracranial aneurysms: report of 215 familial aneurysms. Neurosurgery 1995, 37:43-46

23. Ronkainen A, Miettinen $H$, Karkola $K$, Papinaho $S$, Vanninen $R$, Puranen $M$, Hernesniemi ]: Risk of harboring an unruptured intracranial aneurysm. Stroke 1998, 29:359-362

24. Elston RC, Guo X, Williams LV: Two-stage global search designs for linkage analysis using pairs of affected relatives. Genetic Epidemiology 1996, I 3:535-558

25. Guo X, Elston RC: One-stage versus two-stage strategies for genome scans. Advances in Genetics 200I, 42:459-47I

26. Guo X, Elston RC: Two-stage global search designs for linkage analysis I: use of the mean statistic for affected sib pairs. Genetic Epidemiology 2000, I 8:97-I I0

27. Guo X, Elston RC: Two-stage global search designs for linkage analysis II: including discordant relative pairs in the study. Genetic Epidemiology 2000, I 8: I I I- I 27

28. Holmans $P$, Craddock N: Efficient strategies for genome scanning using maximum-likelihood affected-sib-pair analysis. American Journal of Human Genetics 1997, 60:657-666

29. Lander E, Kruglyak L: Genetic dissection of complex traits: guidelines for interpreting and reporting linkage results. $\mathrm{Na}$ ture Genetics 1995, I I :24 I-247

30. Kuivaniemi H, Yoon S, Shibamura H, Skunca M, Vongpunsawad S, Tromp G: Primer-extension preamplified DNA is a reliable template for genotyping. Clinical Chemistry

31. Zhang L, Cui X, Schmitt K, Hubert R, Navidi W, Arnheim N: Whole genome amplification from a single cell: implications for genetic analysis. Proceedings of the National Academy of Sciences of the United States of America 1992, 89:5847-585 I

32. Yuan B, Vaske D, Weber JL, Beck J, Sheffield VC: Improved set of short-tandem-repeat polymorphisms for screening the human genome. American Journal of Human Genetics 1997, 60:459-460

33. Olson JM: Relationship estimation by Markov-process models in a sib-pair linkage study. American Journal of Human Genetics 1999, 64: |464-|472

34. Risch N: Linkage strategies for genetically complex traits. I. Multilocus models. American Journal of Human Genetics 1990, 46:222-228

35. Kruglyak L, Lander ES: Complete multipoint sib-pair analysis of qualitative and quantitative traits. American Journal of Human $\mathrm{Ge}-$ netics 1995, 57:439-454

36. Norio R: Diseases of Finland and Scandinavia. In: Biocultural aspects of disease (Edited by: Rothschild H) New York: Academic Press Inc I98I, 359-4|5

37. de la Chapelle A, Wright FA: Linkage disequilibrium mapping in isolated populations: the example of Finland revisited. Proceedings of the National Academy of Sciences of the United States of America 1998, 95:12416-12423

38. de la Chapelle A: Disease gene mapping in isolated human populations: the example of Finland. Journal of Medical Genetics 1993, 30:857-865

39. Peltonen L, Pekkarinen P, Aaltonen J: Messages from an isolate: lessons from the Finnish gene pool. Biological Chemistry HoppeSeyler 1995, 376:697-704 
40. Peltonen L: Positional cloning of disease genes: advantages of genetic isolates. Human Heredity 2000, 50:66-75

4I. Ronkainen A, Hernesniemi J, Ryynänen M, Puranen M, Kuivaniemi H: A ten percent prevalence of asymptomatic familial intracranial aneurysms: preliminary report on 110 magnetic resonance angiography studies in members of 21 Finnish familial intracranial aneurysm families. Neurosurgery 1994, 35:208-2 I 2

42. Vanninen RL, Hernesniemi JA, Puranen MI, Ronkainen A: Magnetic resonance angiographic screening for asymptomatic intracranial aneurysms: the problem of false negatives: technical case report. Neurosurgery 1996, 38:838-840

43. Ronkainen A, Puranen MI, Hernesniemi JA, Vanninen RL, Partanen PL, Saari JT, Vainio PA, Ryynänen M: Intracranial aneurysms: MR angiographic screening in 400 asymptomatic individuals with increased familial risk. Radiology 1995, 195:35-40

44. Casey JR, Petranka JG, Kottra J, Fleenor DE, Rosse WF: The structure of the urokinase-type plasminogen activator receptor gene. Blood 1994, 84: II5I-II56

45. Ni B, Du Y, Wu X, DeHoff BS, Rosteck PR Jr, Paul SM: Molecular cloning, expression, and chromosomal localization of a human brain-specific $\mathrm{Na}(+)$-dependent inorganic phosphate cotransporter. Journal of Neurochemistry 1996, 66:2227-2238

46. Bermingham N, Hernandez D, Balfour A, Gilmour F, Martin JE, Fisher EM: Mapping TNNCI, the gene that encodes cardiac troponin I in the human and the mouse. Genomics I995, 30:620-622

47. Bhavsar PK, Brand NJ, Yacoub MH, Barton PJR: Isolation and characterization of the human cardiac troponin I gene (TNNI3). Genomics 1996, 35: II-23

48. Joutel A, Corpechot C, Ducros A, Vahedi K, Chabriat H, Mouton P, Alamowitch S, Domenga V, Cecillion M, Marechal E, Maciazek J, Vayssiere C, Cruaud C, Cabanis EA, Ruchoux MM, Weissenbach J, Bach JF, Bousser MG, Tournier-Lasserve E: Notch3 mutations in CADASIL, a hereditary adult-onset condition causing stroke and dementia. Nature 1996, 383:707-710

49. de Meeus A, Stephan E, Debrus S, Jean MK, Loiselet J, Weissenbach J, Demaille J, Bouvagnet P: An isolated cardiac conduction disease maps to chromosome 19q. Circulation Research 1995, 77:735-740

50. Brink PA, Ferreira A, Moolman JC, Weymar HW, van der Merwe PL, Corfield VA: Gene for progressive familial heart block type I maps to chromosome I 9q I 3. Circulation 1995, 91: I633-1640

51. Ophoff RA, Terwindt GM, Vergouwe MN, Frants RR, Ferrari MD: Involvement of a $\mathrm{Ca2}+$ channel gene in familial hemiplegic migraine and migraine with and without aura. Headache 1997, 37:479-485

52. Jodice C, Mantuano E, Veneziano L, Trettel F, Sabbadini G, Calandriello L, Francia A, Spadaro M, Pierelli F, Salvi F, Ophoff RA, Frants RR, Frontali M: Episodic ataxia type 2 (EA2) and spinocerebellar ataxia type 6 (SCA6) due to CAG repeat expansion in the CACNA IA gene on chromosome 19p. Human Molecular Genetics 1997, 6:1973-1978

53. Onda H, Kasuya H, Yoneyama T, Takakura K, Hori T, Takeda J, Nakajima T, Inoue I: Genomewide-linkage and haplotype-association studies map intracranial aneurysm to chromosome 7q I I. American Journal of Human Genetics 200I, 69:804-819

\section{Pre-publication history}

The pre-publication history for this paper can be accessed here:

http://www.biomedcentral.com/1471-2350/3/7/prepub

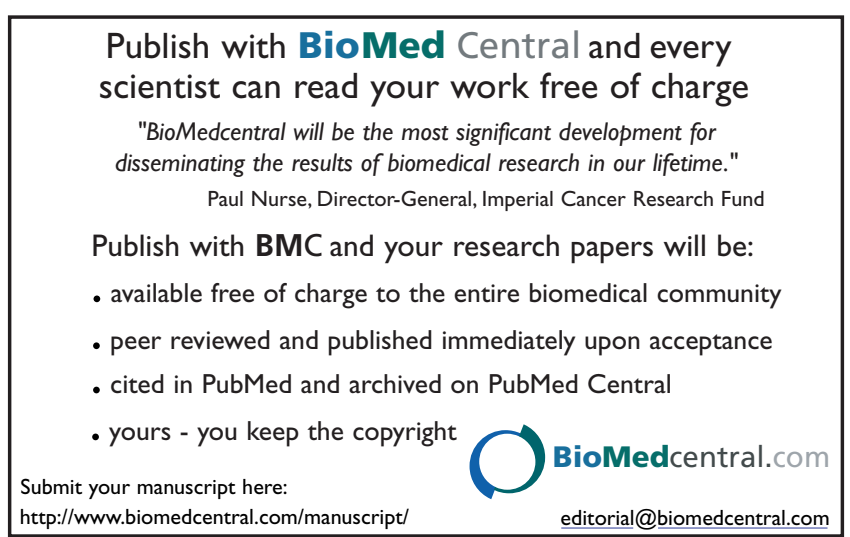

